\title{
Study on Principles of System Information Safety from a Theoretical Perspective
}

\author{
Haixia Lei* \\ School of resources and safety engineering \\ Central south university \\ Changsha, China \\ E-mail: csulhx@163.com \\ * Corresponding Author \\ Chao Wu \\ School of resources and safety engineering \\ Central south university \\ Changsha, China \\ E-mail:wuchao@mail.csu.edu.cn
}

\author{
Nan Jia \\ School of resources and safety engineering \\ Central south university \\ Changsha, China \\ E-mail: jianan1989@csu.edu.cn
}

\begin{abstract}
To study the root of phenomenon from macroscopic view of system, in the case of current problem of information safety events occurred frequently. Analyzed system information essence and interactional characters, mechanism and rule between information flow and system, and clarified the definition and connotation of system information safety. Extracted six core subordinate principles, including carrier essential principle, transmission principle, the principle of resources process management, the principle of resources management regulations, $3 \mathrm{E}$ principle and asymmetry principle, the connotation of the six principles were analyzed. A set of relative and intact program to make information running safely and the corresponding judgment was created. Confirm the duty that people the main body should be take on in information safety and classification, and apply the extracted principles to instruct the performance at work. Finally, proposed some ways to develop good information safety literacy.
\end{abstract}

Keywords- information; system; safety; subordinate principles; application

\section{INTRODUCTION}

With the arrival of the information era, information resources have become an important standard of measuring country's developmental level. Information technology brought great convenience to human's life. Meanwhile, safety risks also go hand in hand. At present, information safety issues become increasingly prominent, and information safety events are exposed frequently. Safety information system contains three subsystems, including government safety systems, enterprise safety systems and social safety information system ${ }^{[1]}$. Due to information safety issues of subsystems made serious consequences becoming common, ranging from damaging individual rights to affecting smooth production, thereby impede country's economic development, and even endanger country's safety. In terms of personal, whether information safe relate to individual's interest. The exposure of individual information, the privacy particularly, such as the

\author{
Hongqiang Tan \\ School of resources and safety engineering \\ Central south university \\ Changsha, China \\ E-mail: csuthq@163.com
}

selling of disclosed postgraduate information and the leakage of personal railway information causing panic and so on, leading a negative impact for the public. Moreover, personal problems gathering will sublimate social problems easily. In terms of enterprise, effectively security of information safety, not only improve efficiency and effectiveness in certain extent, also could prevent production accidents fundamentally, thus avoid losses, and implement the guiding ideology of "safety first, first prevention". In terms of country, using information theft as the main illegal way, inadequate protection of information may endanger country and the whole nation.

Therefore, master the essence, connotation, characters, operation mechanism and rule of information safety has to be a tendency, and must proceed from overall and macro viewpoint, using systems thinking. In this paper, the movement of system information as the main line, from the height of methodology, summarizing and refining the law and principles should follow from industries and all kinds of systems in the process of realizing information safety, and apply these principles to guide practice, so standardize information using in system, providing fundamental way for solving current problem of information safety.

\section{RESEARCH OBJECT AND ATTRIBUTIVE CHARACTERISTICS OF S YSTEM INFORMATION}

\section{A. Research object}

After checking extensive literatures ${ }^{[2-5]}$, there is no uniform definition of information. The definition of information should be established on the basis of Shannon's, and continuous improvement with the development of times. Try to take account of all attributes characteristics of information in definition, in particular the characteristics of reliability and completeness ${ }^{[2]}$. Information is a collection of things and their attributes identified [3], and it can't exist without substances. Professor Wu Chao in Literatures [6-7] proposed safety 
science principles, and built a safety science system. Safety science principles contain 5 first principles and their subordinate 5 secondary principles. Among them, indicated safety system is the workplace of accidents and disasters; safety system thinking is the core idea of safety science; safety system science is the main subject of safety science ${ }^{[6]}$. And Information is the essence and soul of safety system, the importance of exploring information safety is evident. The relationship between research object and related theory disciplines showed in Fig.1.
Purpose

Means

Root

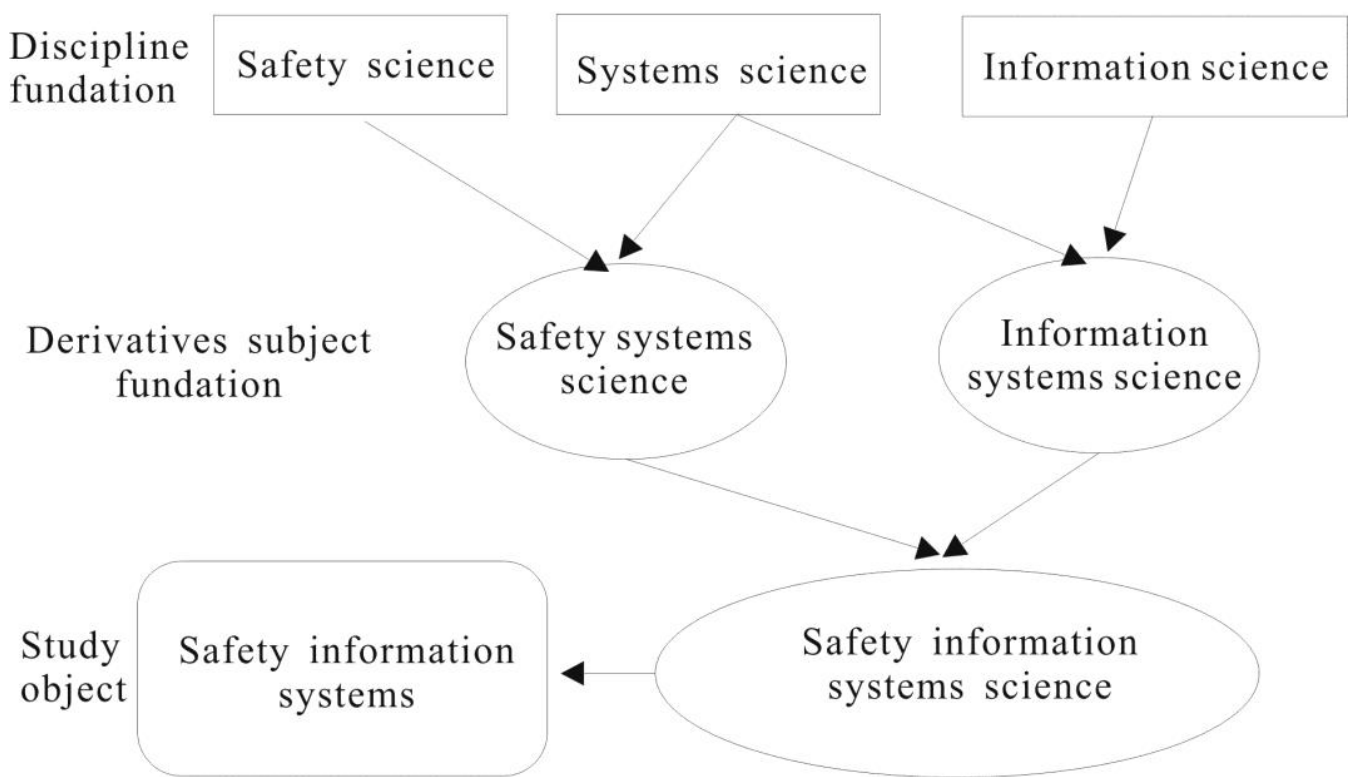

Figure 1. The relationship between research object and related theory discipline

Use the reference [10], and try to define the research object that system information safety as follows:

The system consists of man, computer hardware \& software, network, data, management and other elements through a certain way combined together. In the process of information collecting, processing, analysis, evaluation, storage, management, guarantee information completely, reliably and confidentially communicate, according to the feedback of deviation information, and adjust and control system operation timely, and provide an important judgment basis for final decision programs.
There are many division criteria of information depending on different purpose and focus, leading to many types. In this paper, all information can be understood as safety-related information, namely safety information. By summarizing the references [8-11], the safety information can be classified according to actual situation, mainly from perspectives of philosophy, attribute, intrinsic, source, functions and status, and divided into 9 types. The characteristics and examples of safety information have shown in Table I.

TABLE I. SAFETY INFORMATION CLASSIFICATION FROM DIFFERENT PERSPECTIVES AND OWN CHARACTERISTICS AND EXAMPLES

\begin{tabular}{|c|c|c|c|}
\hline Division basis & Specific Types & Characteristics & Examples \\
\hline \multirow[b]{2}{*}{ Philosophy } & Ontology information & $\begin{array}{l}\text { Object itself carry; objective, not changed for subjective } \\
\text { etc. }\end{array}$ & Scene information \\
\hline & Epistemology information & $\begin{array}{l}\text { Conversion through analysis of human brain; with a certain } \\
\text { subjective etc. }\end{array}$ & Analysis report of accidents \\
\hline \multirow[t]{2}{*}{ Attribute } & Natural safety information & $\begin{array}{l}\text { Most direct and objective; may be hidden social safety } \\
\text { information need converted etc. }\end{array}$ & Dragonflies flying low \\
\hline & Social safety information & Complex; extensive sources etc. & Production information \\
\hline \multirow{2}{*}{ Source } & External safety information & Static; standardized etc. & Environmental information \\
\hline & Internal safety information & $\begin{array}{l}\text { Objective reality reflection during operation; dynamic } \\
\text { control etc. }\end{array}$ & Ingredient information \\
\hline \multirow{3}{*}{$\begin{array}{l}\text { Functions and } \\
\quad \text { Status }\end{array}$} & Safety instructions information & $\begin{array}{l}\text { Relative stability; performing system operational purpose } \\
\text { etc. }\end{array}$ & Safety goal of production \\
\hline & Safety dynamics information & $\begin{array}{l}\text { Mainly foundation for system adjustment; produce different } \\
\text { results at same conditions etc. }\end{array}$ & Timely information \\
\hline & Safety feedback information & $\begin{array}{l}\text { Judgement of fitting expected standard; decision-making } \\
\text { basis etc. }\end{array}$ & Strange information \\
\hline
\end{tabular}

System itself can be regarded as a large information carrier, it not only includes status of reflecting own and internal components, and interact with the information from outside namely external information. Meanwhile, there are exist information exchange in internal components. Information enter system, they through a series of complex channel with information in system, after the information overlap and interplay, then produce 


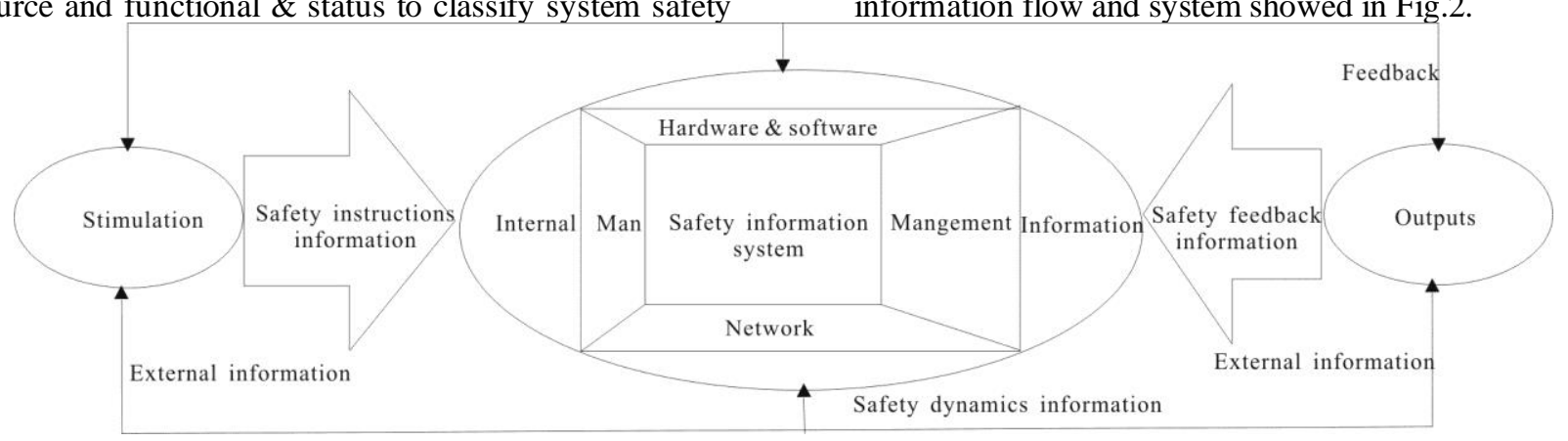

Figure 2. The interactional relationship between information flow and system

\section{B. Attributive characteristics of system information}

System information safety consider information as object, and use various methods of system as means to achieve the purpose of information safety ultimately. In the process, emphasized the following important attributive characteristics of system information.

\section{1) The reliability of system information}

It is an important property of system information, and plays more prominent role compared to accuracy in system. Accuracy only emphasizes the objective reality of things expression of system information, and reliability emphasizes more on local conditions, reflecting applicability of system information. The level reliability affects system operation directly.

2) The confidentiality of system information

It seems particularly important while information sharing involves the interests of individuals, enterprises and country. With the continuous development of science and technology, the methods of guarding confidentiality have become increasingly sophisticated, such as the technologies of cryptography, trusted computing, network safety and information hiding.

\section{3) Sharing of system information}

Everything has two sides, both advantages and disadvantages. The special characteristic makes the information differ from matter and energy, and anyone can use the same information but not wear. It is the important factor that enterprises are no longer limited by space and region, and spread all over the country even the global. However, it also leads to information safety decreasing greatly. It becomes an important breakthrough of lawless elements, and causes vicious events.

From a view of system stability, input and output will be the only way to exchange between information and environment. Actually, system often in a dynamic, and every link may exchange with environment after information flow into system, thereby increasing the leakage risks of system information. Reduce the exchange between processing links of system and environment, it will be good for improving confidentiality of information; to increase confidentiality and applicability of information, it should be reverse. So it can adjust instruction immediately, and change structure of system to adapt environment and develop itself. Therefore, in practically, weigh the pros and cons comprehensively, and make the right decisions to maximize information resources use.

\section{PRINCIPLES OF SYSTEM INFORMATION SAFETY}

Principles of system information safety aimed at study the system, which consist of man, computer hardware \& software, network, data, management and other elements, information as leader of system running direction and objective reactor of system status. In the process of complex interactions with system, ensure information convey and present smoothly, and achieve information value, meanwhile avoid negative effects which from related man, things and others, the common law should be followed.

Contents of principles of system information safety mainly include the following two aspects:

Essential attribute of information. Understand essence, characteristics and motion law of information profoundly, including reliability, confidentiality and sharing features, and gathering, analysis, evaluation, storage, management, error representation of information etc., in order to create good conditions and environment for system efficient operation and desired goal achieving.

Complex effect between information and system. System information is always the heart of system running, the ultimate study objective is expression smoothly and meeting requirements, while information have complex interactions with systems. Information itself without emotion, and generate judgement standard after added human service needs. Thus information expression is bound to a certain extent, running in the track that human made.

According to main contents of principles of system information safety, and around information safety of system, six core subordinate principles were extracted, including carrier essential principle of system information safety, transmission principle of system information safety, the principle of resources process management of system information safety, the principle of resources management regulations of system information safety, $3 \mathrm{E}$ principle of system information safety and asymmetry principle of system information safety. 


\section{A. Carrier essential principle of system information} safety

Monism clarified the relationship of substance and information of objects from a perspective of philosophy [5], and indicated any system information that needs a certain form of substance to display, which information and carrier go hand in hand. To protect information safe should fundamentally ensure carrier not susceptible to outside. Carriers of system information have many kinds, such as substance, material fluctuation signal and symbol carrier ${ }^{[8]}$. Carriers have character of multiple brokerage, and infinite in some case that made information can be hiding deeply. The exchange of information actually is substance interaction that carries attached, and the type and status of carrier affect information expression directly. The principle means that the communication of system information need carrier at any time, and guarantee carrier safe could protect information safe fundamentally. Broaden information carrier type to make it more portable, reliable, and adapt to environment.

\section{B. Transmission principle of system information safety}

The root cause of information exists is information transmission. To realize the value of information, it will be used by others eventually. The process of system information reflects the content of itself and made outside understood called transmission, the fundamental purpose is to transmit system information, including receiving, analysis, processing, evaluation, feedback, storage, extraction and other sectors of system information. The process is equivalent to a series circuit, leading to incomplete system information while any part performs omissions, and may affect operation smoothly, even cause serious consequences. The transmission process of information is the control of system running, which is the most vulnerable link in attack. Meanwhile, it is the best time to prevent, and the importance of transmission safety process is self-evident. Understood various aspects of system information transmitting clearly, and grasp the internal mechanisms of system information, thus can implement work better, and make contingency measures in advance to minimize the accidents consequences.

\section{The principle of resources process management of system information safety}

Information resources are mainly divided into macro and micro. Therefore, management not only could base on macro-social level, but also form micro management of personal and enterprise. The two types of information resources could convert under certain conditions. Microinformation resource can achieve a qualitative leap when reaches a certain amount and meet certain conditions, and rise to macro-social of information resources. For example, people in daily social activities, disclose own private information has become a trend. Because of defective system of obtaining units or mismanagement, lead to events of mass personal information disclosure, and gradually become social issues of information safety. Management support foundation for transmission, it through process management of system information resources, and achieve accurately and reliably at any time. The dynamic of system also requires process management of system information resources, so that enable monitor, control and adjust timely.

\section{The principle of resources management regulations of system information safety}

Information safety events happened frequently, which reflect information technology needs further improved, and illuminate imperfect country's regulations of resources management regulations of system resources. Victims have no laws to guard their rights after lawbreakers commit crime; Criminals lack of proper sanctions and become more rampant. It is urgent to improve the laws and regulations of management of information resource, and provide a legal way for the defenders. When the laws and regulations have developed, then related-information officers could make more clearly of their rights and obligations. Information technology and legal system are the internal and external factor of guarding system information safety, only they two-pronged interaction could achieve information safety from inside to out.

\section{E. 3 E principle of system information safety: efficiency, effectiveness and economy}

Under the existing condition and limited information resources, this paper achieve efficiency, effectiveness and economy through rational organization, distribution, management and other ways to in order to maximize organization value. There are many solutions for solving problem, usually the comprehensive benefits should be considered to make choice, and $3 \mathrm{E}$ principle is the sole criterion based on people-oriented policy. Choice is a process of information regeneration, through discriminating and obtaining advantage of the existing information resources to achieve $3 \mathrm{E}$, and combined with the goals and expectations of specific problems, making objective information into decision with subjective color. The decision-making process is the process of in-depth analysis of system information, and many factors impact interpreting ability of decision-makers, they are educational background, living environment, learning ability and other factors. Comply with $3 \mathrm{E}$ principle will be form an optimal decision system.

\section{F. Asymmetry principle of system information safety}

The depth of information resources obtaining affect decision of makers directly, thereby affect individuals, enterprise and country's macro-strategy, and play a role from surface to point, result in different outcomes of personal future, enterprise development and national security. The main causes of asymmetry of system information safety have the following two aspects:

1) Lack of searching capability of system information

Limited sources of system information resources lead to incomplete information searching. In the information overload era, a flood of information has brought unknowingly trouble, and extract required information quickly and accurately has to be a necessary skill. The constant of objective existence information resources is equal for any organization, how to get required information in the information ocean become 
the key. Information searching is an initial work in system, in the competition of individuals, businesses or countries, extensive information resources and effective acquisition are foundations for improving competitiveness. Organizations with this advantage at start often have multiplier effect and increase successful chance. Therefore, improve capability of obtaining information could lay solid foundation for smooth operation of system.

2) Differences of interpreting ability in system information

Information resources have rich contents, but get different information with different way of people's interpreting. Information interpreting is subjective, actually the information owns consistent content, but its interpretation varies by people. As if the truth of thing is uniqueness, but exploring road is always spiral, through the development of society and technological, and infinitely close to truth, until finally grasp the truth. During the process of conversion of information content, produce varying interpretation, but there be conversion of readers closer to objective reality which oneupmanship in decision. The consequence of misunderstanding is "a little error may lead to a large discrepancy".

\section{APPLICATIONS OF THE PRINCIPLES OF SYSTEM INFORMATION SAFETY IN RESPONSIBILITIES OF} DIFFERENT ROLES

More centralized system information resources will be the future trend, and information extraction will become simpler and more convenient. Meanwhile, the tasks of information management will become more difficult, consequences of every aspect errors will be more serious by contrast. Therefore, corresponding completing duties of system aspects will be more important. In the system, software and hardware equipment, network and data can be classified into informational technology, and the level of technology depends on contemporary society, relative stability. Initiative of people make uncontrollable, so that duties fulfilling vary due to people. According to information procedure needs, the role of people playing can be divided into resource managers, decision-makers, executives and server of system information safety.

\section{A. resource managers of system information safety}

Resources management of system information includes static and dynamic management. Static management, namely manager be responsible for classify relevant information from all aspects, including various types of related system information, such as related laws and regulations, lessons of accidents, realtime status of monitoring and so on. Static information resources are the source of information providing, and be the final destination of existence. Information management of static system, the most representative may be the archives staffs.

To fulfill task better, they need to make full use of carrier essential principle and the principle of resources management regulations, and make related system information completely, while ensure information safe. Static management compare with dynamic management, that the labor of human more clearer and responsibilities more specific. In dynamic management, everyone involved in system, regardless of their own responsibilities, they have obligation to feedback at least the information status of duties. Dynamic management involved everyone, which put more emphasis on information operations, and relates to carrier essential principle and the principle of resources process management. The ultimate goal of resources management of system information is to extract easily for safety decision -makers.

\section{B. Decision-makers of system information safety}

If the system information is taken as the traveling boat, safety decision -makers are the navigation lights in navigation, and control the direction of entire vessel. Decision-makers grasp it from macro and make strategic plan. According to asymmetry principle, system senior managers are bound to increase public resources grabbing to minimize selection bias caused by information asymmetry. However, even under the conditions of same information resources, different decision-makers may make different choices. The reason is that resource managers providing just raw data, without any processing, and the same amount of objective information for anyone, and the key is information conversion. Analysis and evaluation of information will vary depending on perspective, focus and purpose etc., which produce different results, and value-added of information is the performance of direct purpose of analysis. Safety decision -makers take full advantage of existing information resources, and make best choices based on $3 \mathrm{E}$ principles which meet the actual situation. In the limited time and resources, the authors strive for efficiency, effectiveness and economy, and thus maximize organizational effectiveness.

\section{Executives of system information safety}

A person's energy and ability is limited, and make everything impossible. Thus, social needs individual divided labor and in charge of duties, and it can advance smoothly and orderly. It's the same in system, making every position of people be equal to their talent and quality. Executives of system information safety held positions widely, and could spread all over the system. Only each executive cooperates closely that could finalize the strategic planning of safety decision -makers. Executives of information safety become the first for monitoring actual information, once system information appears strange alert, they feedback error information immediately, and control situation and adjust operation timely. Executives of system information safety are the source of actual situation, which will be important basis of decision. Therefore, in the course of system running, must always recognize transmission principle and the principle of resources process management, and grasp the mechanism and fulfill responsibility to ensure system operation smoothly.

\section{Server of system information safety}

The original intention of system is to meet some demand of human, and the people obtaining called service object of system information. For example, although the direct output of some systems is product, 
the ultimate goal is products selling, and providing supply for customer required; the industries which use customer's information for services, system only as tool and means of service, and reflect fundamentality of service object of system information safety. The leakage of postgraduate information, vulnerability of grabbing rail ticket system caused leakage of personal information, which brought more profound reflection. As the object of information services enjoying, should know how to protect interests, and use related laws and regulations safeguard legal rights. Use of the principle of resources management regulations, and call for related regime improving to support defenders, while take legal action to suppress the arrogance of criminals, and ensure personal information safety.

\section{THE WAYS OF IMPROVING THE LITERACY OF INFORMATION SAFETY}

The literacy of information safety of person has determined the ability of information processing to some extent, and provides guarantee for human life-long learning. In system, improve the quality of personnel literacy of information safety, which good for grasping and using the principles of system information safety to do job better.

This paper mainly takes account of internal and external factors to improve the literacy of information safety of citizens. Internal factors include the personal educational background, work environment, learning ability, personality, and so on; external factors mainly indicate social environment, including related laws and regulations of information and ethics of information safety that society forming. Specific ways to improve the literacy of information as follows:

1) Pay attention to cultivate related capabilities of information safety

Be conscious of the needs of life and work, and dig the potential continually. Cultivate abilities of searching, processing and evaluating information. Particularly, develop skills for work. Individuals, enterprises and institutions can through regular training to improve the staff's capacity and quality of information safety.

\section{2) Provide good external environment}

State departments build sound laws and regulations, which can provide law for illegal activities and protecting rights of citizens. Citizens live in long-term legal and orderly social environment, forming deeprooted ethical qualities imperceptibly, and abide by obligations of information management.

\section{CONCLUSIONS}

Clarify the necessity of system information safety as research object, and determine its definition and connotation. According philosophy, attribute, intrinsic, source, functions and status, sum up the interactional relationship between information flow and system from the perspective of source and function.

Based on the analysis of the characteristic of system information and central theme of the principles of system information safety, identify two main contents of the principles of system information safety, they are essential attribute of information and the complex action between information and systems.
On the center of information safety in system, extract part of the principles of system information safety, including carrier essential principle of system information safety, transmission principle of system information safety, the principle of resources process management of system information safety, the principle of resources management regulations of system information safety, $3 \mathrm{E}$ principle of system information safety and asymmetry principle of system information safety.

Confirm the responsibilities of social roles in information safety of system, and use extracted principles to guide work. On this basis, propose methods to improve the literacy of information safety.

\section{ACKNOWLEDGEMENT}

The authors wish to acknowledge the editors and the anonymous reviewers for valuable advice on this work. This work was supported by the second kinds of special projects of the Ministry of Education (TS2318).

\section{REFERENCES}

[1] LI Juan-juan and XU Shuang-pei, "Application and Analysis of Safety Information System," Mechanical management and development, vol. 24, Oct. 2009, pp. 194-196, doi: 10.3969/j.issn.1003-773X.2009.05.099.

[2] WANG Yong, “Analysis and Betterment of Shannon's Information Definition," Journal of information, vol. 27, Aug. 2008, pp. 57-60,10.3969/j.issn.1002-1965.2008.08.018.

[3] DENG Yu, DENG Fei, and DENG Hai, et al. "Standardization of Information Definition," Medical information, vol. 19, Jul. 2006, pp. 1143-1146,10.3969/j.issn.1006-1959.2006.07.016.

[4] JIANG Lu, and FAN Zhi, "Discussion on the Definition of Information," Journal of systemic dialectics, vol. 12, Apr. 2004, pp. 28-30, doi: 10.3969/j.issn.1005-6408.2004.02.009.

[5] WANG Zhe, "A Commentary on Two Kinds of Definitions of Information," Journal of huazhong university of science \& technology (social science edition), vol. 21, Jan. 2007, pp. 90-94, doi: 10.3321/j.issn:1671-7023.2007.01.017.

[6] WU Chao and YANG Mian, "Study of Safety Science Principles and Their Constructions," China safety science journal, vol. 22, Nov. 2012, pp. 3-10, doi:1003-3033(2012)110003-08.

[7] WU Chao and YANG Mian, "Connotations of 25 Principles of Safety Science," Hunan safety and disaster prevention, Feb. 2013, pp. 42-45, doi: 10.3969/j.issn.1007-9947.2013.02.018.

[8] WU Chao. Methodology of Safety Science. Beijing: China Labor and Social Security Publishing House, 2011:149-166.

[9] ZHAN Hong-chang and CHEN Guo-hua, "Probing into the Development of Safety Management Information System," Industrial safety and environmental protection, vol. 29, Mar. 2003, pp. 38-41, doi:10.3969/j.issn.1001-425X.2003.03.017.

[10] LIU Lu. Information System: principles, methods and applications. Beijing: Higher Education Press, 2007:1-33.

[11] ZHONG Yi-xin. Information Science Principles (The third edition). Beijing: Beuing University of Posts and Telecommunications Press, 2002:45-69.

[12] SHEN Chang-xiang, ZHANG Huan-guo, and FENG Deng-guo, et al. "Information Safety Review," Science in china, vol. 37, Feb. 2007, pp. 129-150, doi: 10.3321/j.issn:10069275.2007.02.001.

[13] XIANG Ying and LI Xiang-jun, "Research on Implementation of Resource Discovery System in University Libraries," Information science, vol. 30, Nov. 2012, pp. 1681-1690, doi: 10.13833/j.cnki.is.2012.11.023.

[14] HE Chao, SONG Xue-feng and LI Xian-gong, "Research and Probe on Information Management System of Coal mine safety supervision," Industry and mine automation, vol. 39, Jan. 2013 pp. 96-99, doi: 10.7526/j.issn.1671-251X.2013.01.025. 